\title{
A cytogenetical and molecular analysis of the ribosomal cistrons of Allium sphaerocephalon L. (Liliaceae)
}

\author{
M. A. GARRIDO-RAMOS, M. JAMILENA, R. LOZANO, C. RUIZ REJÓN \& M. RUIZ REJÓN \\ Departamento de Biología Animal, Ecologia y Genética, Facultad de Ciencias. Avda. Fuentenueva s/n, Universidad de \\ Granada, 18071 Granada, Spain
}

\begin{abstract}
Allium sphaerocephalon is a species with a high number of secondary constrictions and with intraand interindividual variation in their number. We analysed whether all the secondary constrictions are involved in nucleolus formation, whether the same variability exists in the number of NOR, and the mechanism(s) responsible for this variability. Our cytological data have shown that (i) all the secondary constrictions may be involved in the nucleolus organization, (ii) the variability in number is in accordance with the numbers of NOR, and (iii) the variability could be due to unequal exchanges among ribosomal genes on homologous and non-homologous chromosomes. Ribosomal DNA sequence homogeneity detected in this species supports this conclusion.
\end{abstract}

Keywords: Allium, NOR variability, rDNA sequence homogeneity.

\section{Introduction}

Many studies concerning the nucleolar organizer region (NOR) have revealed this area as a very variable region of the eukaryotic chromosome. While there are species like rye (Appels et al., 1980) or maize (Givens \& Phillips, 1976) in which the number of NOR is constant, there are, in contrast, other cases such as man (Ferraro \& Prantera, 1988), mouse (Suzuki et al., 1990), some species of salmonids (Phillips et al., 1988) or of the genus Allium (Schubert \& Wobus, 1985), in which the number of NOR varies between individuals or even between cells. Possible explanations for these variations have been attributed to mechanisms such as activation-inactivation (Ferraro \& Prantera, 1988), duplication-deletion (Sato, 1981; Jamilena et al., 1990), unequal crossing-over (Suzuki et al., 1990), or even transpositional phenomena (Schubert \& Wobus, 1985). On the other hand, even when rDNA has one or more chromosomal locations it is known that rDNA sequences have a high degree of homogenization and this has been explained as being due to unequal genetic exchanges as reported by Arheim et al. (1980) for man and by Suzuki et al. (1990) for Mus musculus. The same process, which produces sequence homogenization, can also increase or decrease ribosomal RNA gene number, not only in homologues but also between non-homologous chromosomes (Arheim et al., 1980; Suzuki et al., 1990).

In this paper, we analyse by cytogenetic and molecular methods the ribosomal cistrons of Allium sphaerocephalon, an exceptional species in the genus Allium, with a multichromosomal location of NOR and interindividual variability in their number (Pastor, 1982).

Our data demonstrate that all the secondary constrictions are involved in nucleolus formation and that the intra- and interindividual variability in the number of NOR can be due to recombination exchanges among ribosomal genes on homologous and non-homologous chromosomes.

\section{Materials and methods}

One population (composed of 21 individuals) of Allium sphaerocephalon L. from Padul (Granada, Spain) was analysed. Meiotic analyses were performed on flower buds fixed in alcohol-acetic acid 3:1 and stained in 1 per cent acetic carmine. Root tips were pretreated for $12 \mathrm{~h}$ in 0.2 per cent colchicine at $4^{\circ} \mathrm{C}$ for mitotic analysis and fixed in alcohol-acetic acid 3:1. Conventional staining was done with 2 per cent acetic orcein. Silver staining was performed according to Kodama et al. (1980). For the in-situ hybridization technique the $\mathrm{pR} 12$ probe containing radish rDNA 
(Delseny et al., 1983) was labelled with 11-biotindUTP according to 'Nick Translation System' (GibcoBRL). The slides were pretreated with $100 \mu \mathrm{g} \mathrm{ml}^{-1}$ of RNase in $2 \times$ SSC and the hybridization method was performed according to Rayburn \& Gill (1985). The biotinylated probe was detected with a streptavidine-alkaline phosphatase conjugate detection system obtained from Gibco-BRL. DNA was isolated for Southern blot analysis as previously described by Dellaporta et al. (1985) from frozen leaves of 10 different individuals with a different number of NOR. Total DNA was digested with the endonucleases HindIII, $B a m \mathrm{HI}$ and EcoRI following the protocols provided by the supplier (Boehringer Mannheim) and fractionated by electrophoresis in 0.7 per cent agarose gels in TBE (Tris-Borate-EDTA) buffer at $1.5 \mathrm{~V} \mathrm{~cm}^{-1}$ for 16 h. HindIII restriction fragments of lambda DNA were used as molecular weight markers. DNA frag- ments were blotted to a Hybond $\mathrm{N}$ (Amersham) nylon membrane as described in Sambrook et al. (1989) and the filters were baked at $80^{\circ} \mathrm{C}$ for $2 \mathrm{~h}$. The wheat rDNA probe pTA 71 (Gerlach \& Bedbrook, 1979) was used for hybridization. Probe labelling, hybridization and detection procedure were carried out using the nonradioactive biochemiluminiscence (ECL) gene detection system provided by Amersham following the protocols provided by the manufacturer.

\section{Results}

Conventional staining methods reveal four pairs of chromosomes with secondary constrictions in Allium sphaerocephalon $(2 n=16)$ : the fifth pair of the karyotype has a secondary constriction very near to the centromere, the sixth and the seventh pairs have intercalary secondary constrictions, and the eighth pair has
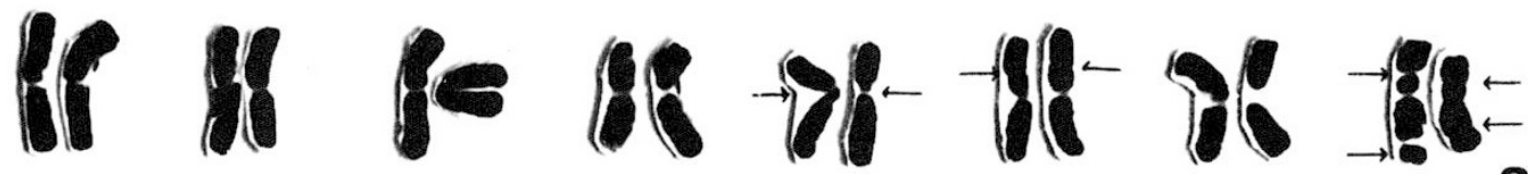

a
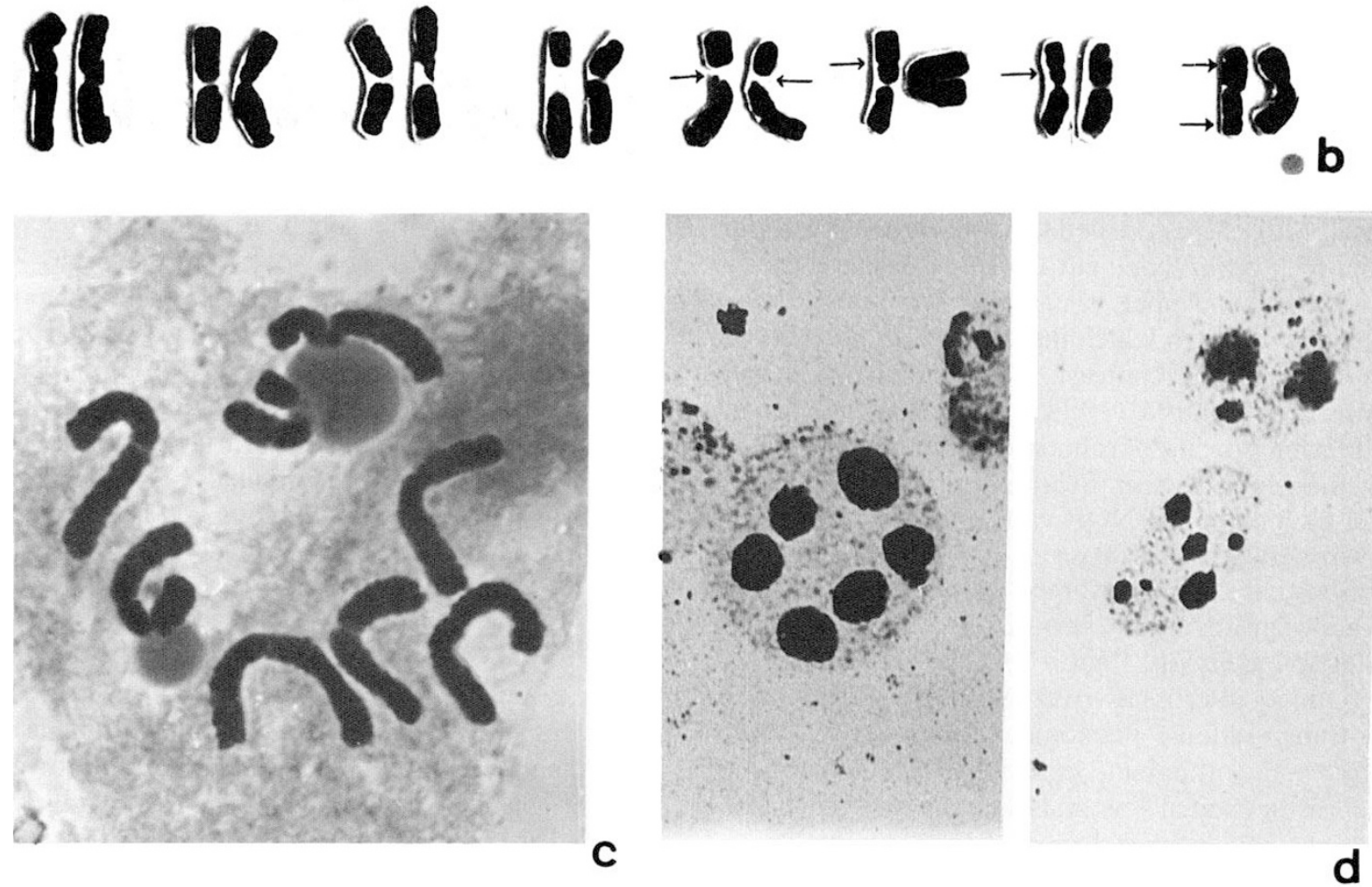

Fig. 1 Conventional staining of mitotic and meiotic cells of $A$. sphaerocephalon $(2 n=16)$. (a, b) Karyotypes obtained from cells with eight (a) and six (b) secondary constrictions (arrows); (c) pollen mother cell $(n=8)$. Three secondary constrictions are actively engaged in nucleolus formation. Observe also two chromosomes associated with one nucleolus (d). Interphases nucleoli and micronucleoli. Bar represents $10 \mu \mathrm{m}$ in all figures. 
two, one in each arm. However, the number of secondary constrictions may vary between the different individuals (and even between cells of the same individual), from two to eight (Fig. 1a and b). All these secondary constrictions are actively engaged in the synthesis of nucleoli as can be seen in diplotene and pollen cells (Fig. 1c). Frequently, two or more bivalents or chromosomes are associated with a single nucleolus.

After silver staining, four to eight NOR are detectable in metaphase (Fig. 2 and Table 1). The locations of these active NOR are normally coincident with the secondary constrictions. However, in one individual there was a NOR in one chromosome of the second pair (see Fig. 2d). The intensity of Ag-staining differed between the different NOR and the intensity of each NOR could vary between cells and individuals, especially for NOR of chromosomes 6 and 8 . The maximum numbers of nucleoli in interphases and prophases corresponded to the numbers of active NOR (see Table 2 for quantitave data from three individuals). In some prophase cells two or more chromosomes were associated with one nucleolus. Micronucleoli occurred in some cells (Fig. 1d and Table 2). In-situ hybridization confirmed the data obtained by silver staining (Fig. 3 and Table 3 ) in five individuals of Allium sphaerocephalon. The intensity of the signal, comparable to silver bands, varied between cells and individuals.

When the total DNA was digested with restriction endonucleases no interindividual variability of the rDNA appeared among the 10 individuals analysed, i.e. all the individuals had the same HindIII bands, the same BamHI bands and the same EcoRI bands. HindIII showed a prominent band of $12.7 \mathrm{~kb}$ and a band of higher molecular weight not cleaved (Fig. 4a). DNA digested by BamHI showed a major band of $12.7 \mathrm{~kb}$
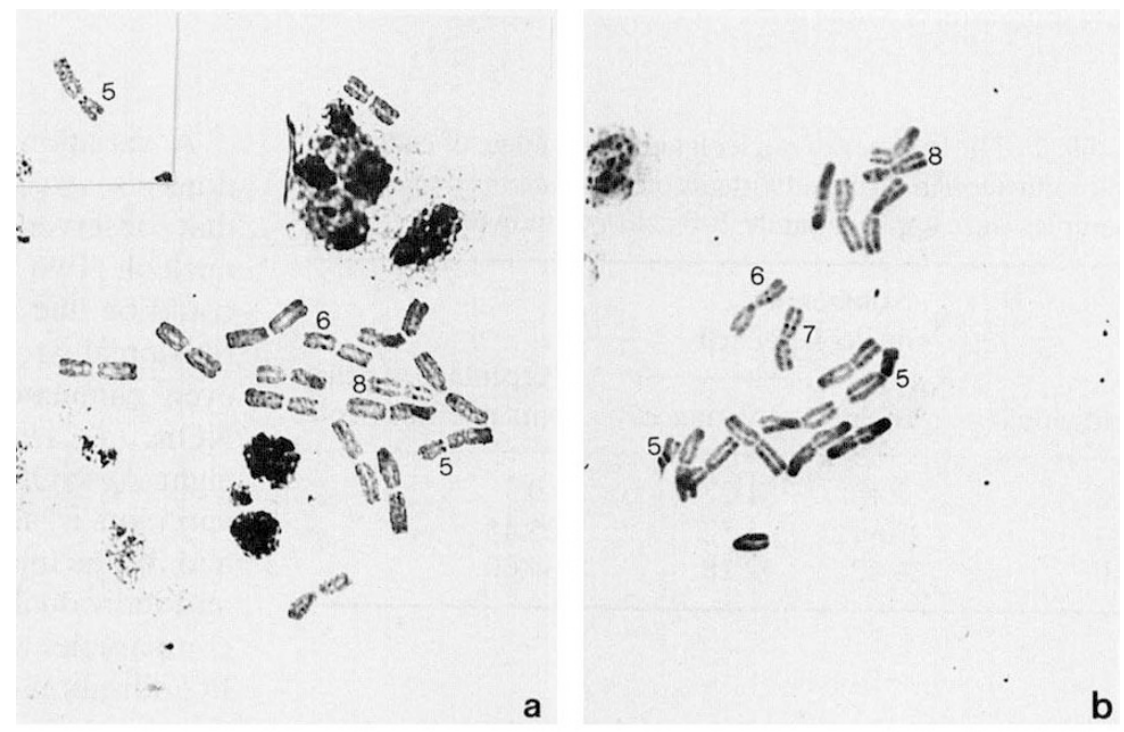

Fig. 2 Silver-staining of metaphase chromosomal plates. Numbers indicate the chromosome pair with active NOR. Cells with five ( $a$ and $b$ ), seven (c) and eight $(d)$ active NOR are shown.
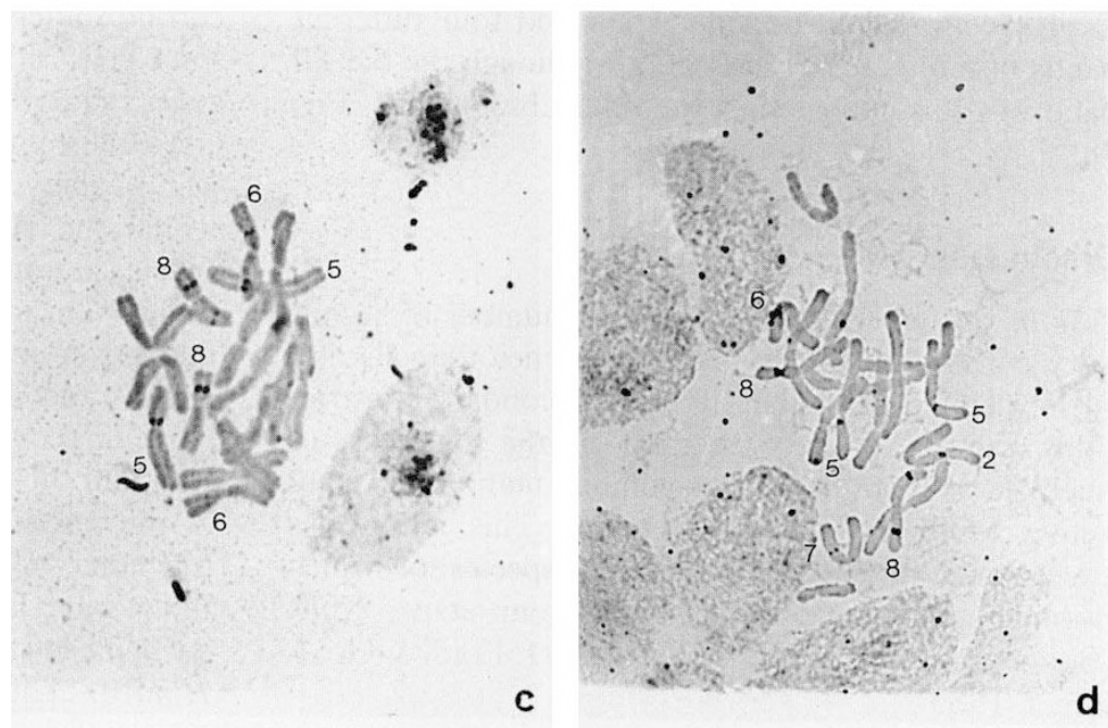
Table 1 Intra- and interindividual variability of the number of NOR (Ag-staining) from 10 individuals of $A$. sphaerocephalon. Samples were normally more than 10 cells per individual, except where marked with an asterisk

\begin{tabular}{|c|c|c|c|c|c|c|c|}
\hline \multirow[b]{3}{*}{ Individual } & \multicolumn{6}{|c|}{ Chromosome pair } & \multirow{3}{*}{$\begin{array}{l}\text { Mean number o } \\
\text { NOR per cell }\end{array}$} \\
\hline & \multirow[t]{2}{*}{2} & \multirow[t]{2}{*}{5} & \multirow[t]{2}{*}{6} & \multirow[t]{2}{*}{7} & \multicolumn{2}{|l|}{8} & \\
\hline & & & & & sa & la & \\
\hline 1 & 0 & 2 & 1.83 & 0 & 1.83 & 0.83 & 6.5 \\
\hline 2 & 0 & 2 & 1 & 0 & 1.50 & 0.50 & 5 \\
\hline $3^{*}$ & 0 & 0 & 2 & 1 & 1 & 0 & 4 \\
\hline $4^{*}$ & 0 & 2 & 1 & 0 & 1 & 0 & 4 \\
\hline $5^{*}$ & 0 & 2 & 2 & 0 & 1 & 0 & 5 \\
\hline 6 & 1 & 2 & 1 & 1 & 2 & 1 & 8 \\
\hline 7 & 0 & 2 & 1.20 & 0.60 & 1.20 & 0.80 & 5.8 \\
\hline 8 & 0 & 1 & 1.50 & 0.50 & 1.50 & 1 & 5.5 \\
\hline 9 & 0 & 2 & 1 & 1 & 2 & 1 & 7 \\
\hline 10 & 0 & 1.80 & 1.60 & 0 & 1.20 & 0.60 & 5.2 \\
\hline
\end{tabular}

$\mathrm{sa}=$ short $\mathrm{arm} ; \mathrm{la}=$ long $\mathrm{arm}$.

Table 2 The number of nucleoli and percentage of cells with micronucleoli in three individuals of $A$. sphaerocephalon. Samples were approximately 200 cells per individual

\begin{tabular}{rlll}
\hline & \multicolumn{2}{l}{$\begin{array}{l}\text { Number of } \\
\text { nucleoli per cell }\end{array}$} & \\
\cline { 2 - 3 } Individual & Mean & Variance & $\begin{array}{l}\text { Percentage of cells } \\
\text { with micronucleoli }\end{array}$ \\
\hline 2 & 3.45 & 1.27 & 0 \\
4 & 3.64 & 1.52 & 25.45 \\
10 & 4.43 & 2.28 & 34.60 \\
\hline
\end{tabular}

and two minor bands of 8.5 and $4.2 \mathrm{~kb}$ (Fig. $4 \mathrm{~b}$ ). After EcoRI cleavage all individuals showed four different bands of $5.6,4.2,2.5$, and $0.6 \mathrm{~kb}$ although the $5.6-\mathrm{kb}$ band was less intense than the other three bands (Fig. $4 c)$.

\section{Discussion}

Allium sphaerocephalon has a high number of secondary constrictions. Our analyses of meiotic cells and silver staining show that all these secondary constrictions can be actively engaged in the synthesis of nucleoli. We observed a maximum number of eight active NOR and nucleoli per cell. This number is exceptional in the genus Allium, species of which normally only have from two to four active NOR (Bougourd \& Parker, 1976; Sato, 1981; Loidl \& Greilhuber, 1983).
A variation in the number of secondary constrictions also exists in A. sphaerocephalon coincident with that observed in the number of active NOR and nucleoli. Two sets of data indicate that this variability could be due to a process or processes acting on the ribosomal areas which change (elongate, reduce or even eliminate) the number of rDNA genes in the NOR: (a) Allium sphaerocephalon has from four to eight Ag-NOR in different cells and individuals; this variation is also observed after in-situ hybridization and (b) the intensity of each NOR varies between cells and individuals and some cells showed micronucleoli: comparable variation was observed after in situ hybridization. The latter observation suggests that the variation in intensity of silver staining between chromosomes and the presence of micronucleoli in some cells is due to a decrease in the number of rDNA genes rather than to a process of partial inactivation.

Furthermore, our data from Southern blot hybridization show a high degree of sequence homogeneity within the rDNA of Allium sphaerocephalon. This species has only one tandem repetitive rDNA sequence of $12.7 \mathrm{~kb}$. HindIII found only one recognition site in the rDNA unit to produce a band of $12.7 \mathrm{~kb}$. BamHI has two recognition sites in each repetitive unit. EcoRI has four recognition sites in all ribosomal genes. If we compare these results with those reported for species of the same genus such as Allium cepa (Maggini \& Carmona, 1981) or in the same family, e.g. Scilla peruviana (Carmona et al., 1984), we conclude that $A$. sphaerocephalon has a similar pattern to Bam $\mathrm{HI}$ and HindIII. These data are in agreement with those 

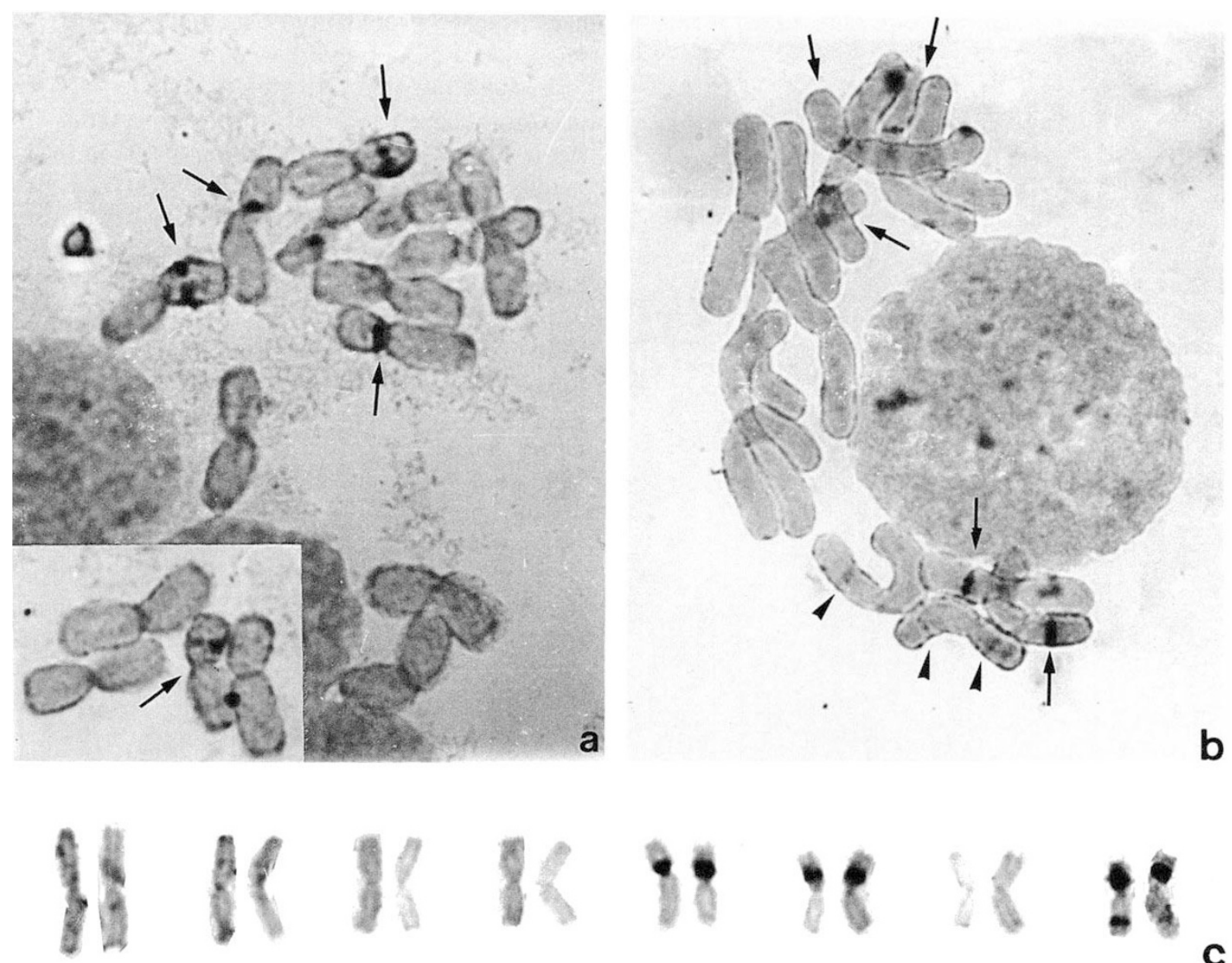

Fig. 3 Somatic metaphase cells after in-situ hybridization and variability in the number of rDNA areas (arrows): cells with five (a), or with five labelled areas and three more poorly labelled (arrowheads) (b). (5c) Karyotype obtained from a cell with eight rDNA regions.

Table 3 Intra- and interindividual variability in the number of rDNA regions shown after $i n$-situ hybridization from five individuals of $A$. sphaerocephalon

\begin{tabular}{lllllll}
\hline \multicolumn{5}{c}{} & \multicolumn{4}{l}{ Chromosome pair } & \\
\cline { 2 - 5 } & 5 & 6 & 7 & 8 & & \\
\cline { 5 - 6 } Individual & & & & sa & la & $\begin{array}{l}\text { Mean number of } \\
\text { sites per cell }\end{array}$ \\
\hline $1^{*}$ & 2 & 2 & 0 & 2 & 1 & 7 \\
$4^{*}$ & 2 & 1.83 & 0 & 1.83 & 1.83 & 6.5 \\
9 & 2 & 1.60 & 1 & 2 & 1 & 7.6 \\
10 & 1.8 & 1.20 & 0.8 & 1.2 & 0.8 & 5.8 \\
11 & 2 & 2 & 0 & 2 & 2 & 8 \\
\hline
\end{tabular}

Samples were normally $>10$ cells per individual except where marked with an *. reported by Maggini (1975) who found a very high sequence homology (about 95 per cent) in the rDNA of the Liliaceae family. However, EcoRI shows one band of $4.2 \mathrm{~kb}$ like the two abovementioned species but in addition another three different bands of $5.4,2.5$ and $0.6 \mathrm{~kb}$. These new bands can be explained if $A$. sphaerocephalon rDNA has gained another two targets for $E c o$ RI that digest the $8.5 \mathrm{~kb}$ band and that have been propagated throughout the ribosomal gene family in this species. This degree of homogenization within ribosomal multigene families in $A$. sphaerocephalon, a species where rDNA are located in multiple chromosomes, may result from unequal genetic exchanges between rDNA from homologous and non-homologous chromosomes because if ribosomal genes on non-homologous chromosomes were genetically isolated from each other then it might be expected that each NOR would evolve independently (Arheim et al., 1980). The same mechanism can also explain the intra- 


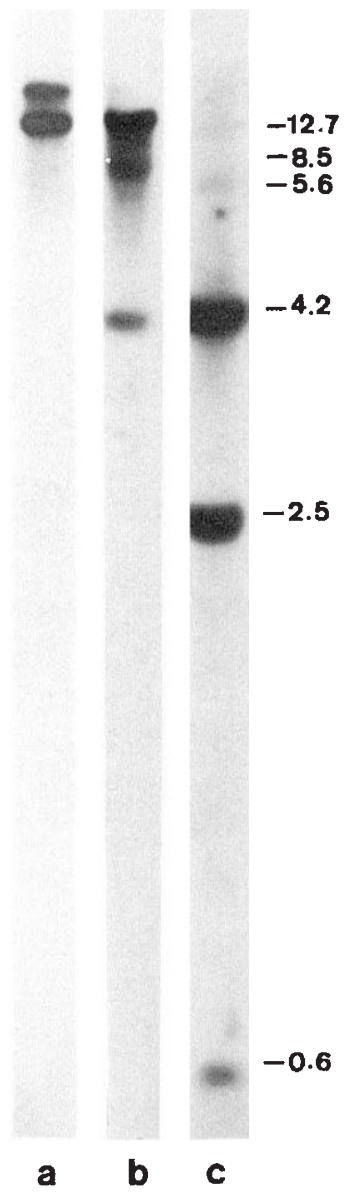

Fig. 4 Restriction pattern of the ribosomal RNA genes of Alium sphaerocephalon digested either with HindIII (a), $B a m \mathrm{HI}$ (b) and EcoRI (c), electrophoresed and hybridized with pTA71 probe. Undigested rDNA observed after HindIII digests may be due to the absence of a specific target for this enzyme in some ribosomal units. BamHI involves two recognition sites in each repetitive unit although either the absence or methylation of a recognition site may prevent digestion in some units producing the observed large band of $12.7 \mathrm{~kb}$ (see, for example Maggini \& Carmona, 1981). Little intensity of the $5.6 \mathrm{~kb}$ band in the EcoRI pattern can be due to the heterologous probe used and less homology in the non-transcribed spacer. Numbers indicate the length of the fragment.

and intervariability in the number and size of NOR. This phenomenon could occur in meiotic or even mitotic prophase or interphase: in fact, we have observed the association or different NOR-bearing bivalents or chromosomes with the same nucleolus in both types of cells. It is important to mention that Loidl (1988), who studied synaptonemal complex formation at the diploid level of $A$. sphaerocephalon, observed the existence of many lateral element thickenings, some associated with the nucleolus. This was interpreted as the expression of a rectifying process in regions which had a higher probability of unequal synapsis such as repetitive rRNA genes areas.

It is also possible, however, that some NOR variants in this species are due to translocations. This is suggested by individuals with one NOR in the second or the seventh pairs. Previously, Guillén \& Ruiz Rejón (1984) have detected the presence of translocations in this species. An exceptional case, not yet described in natural populations, was observed in $A$. sphaerocephalon: the presence of two NOR in the same chromosome, one in each arm. In this case, there was no resultant nucleolar competition such as occurs in barley translocation lines with reconstructed satchromosomes (Nicoloff et al., 1979). In A. sphaerocephalon, when only one active NOR appears, the absence of the NOR in the other arm can be explained by some of the mechanisms discussed above (reduction or elimination by unequal crossing-over and/or translocations), which are more likely to occur than inactivation of the NOR.

\section{Acknowledgements}

The authors wish to thank Dr J. M. Martínez Zapater (INIA, Madrid) and Dr M. Clark (Queen Mary \& Westfield College, London) for providing the pR12 and pTA71 probes, respectively, used in these experiments. This work was supported by a grant from the Spanish CICYT (No. PB87/0881) as well as from the Plan Andaluz de Investigación (Group No. 3186).

\section{References}

APPELS, R., GERLACH, W. L., DENNIS, E, S., SWIFT, H. AND PEACOCK, W. J. 1980. Molecular and chromosomal organization of DNA sequences coding for the ribosomal RNAs in cereals. Chromosoma, 78, 293-311.

ARHEIM, N., KRYSTAL, M., SCHMICKEL, R., WILSON, G., RYDER, O. AND ZIMMER, E. 1980. Molecular evidence for genetic exchange among ribosomal genes on non-homologous chromosomes in man and apes. Proc. Natl. Acad. Sci., U.S.A. 77, 7323-7527.

BOUGOURD, s. M. AND PARKER, J. S, 1976. Nucleolar-organiser polymorphism in natural populations of Allium schoenoprasum. Chromosoma, 56, 301-307.

CARMONA, M. J., DE DOMENICIS, R. I., SALVI, G. AND MAGGINI, F. 1984. Ribosomal RNA genes in biotypes of Scilla peruviana (Liliaceae). Pl. Syst. Evol., 146, 1-11.

DELlAPORTA, S. L., WOOD, J. AND HICKs, J. B. 1985. Maize DNA miniprep. In: Malmberg, R. Messing, J. and Sussex, I. (eds) Molecular Biology of Plants. A Laboratory Course Manual. Cold Spring Harbor Laboratory Press, New York.

DELSENY, M., COOKE, AND PENON, P. 1983. Sequence heterogeneity in radish nuclear ribosomal RNA genes. Plant Sci. Lett., 30, 107-119. 
FERRARo, M. AND PRANTERA, G. 1988. Human NORs show correlation between transcriptional activity, DNase I sensitivity, and hypomethylation. Cytogenet. Cell. Genet., 47, 58-61.

GERLACH, W. L. AND BEDBrook, J. R. 1979. Cloning and characterization of ribosomal RNA genes from wheat and barley. Nucl. Acids Res., 7, 1869-1885.

GIVENS, J. F. AND PHILliPS, R. L. 1976. The nucleolus organizer regions of maize (Zea mays, L.) ribosomal RNA gene distribution and nucleolar interactions. Chromosoma, 57, 103-117.

GUILlen, A. AND RUIZ REJON, M. 1984. The B-chromosome system of Allium sphaerocephalon L. (Liliaceae): Types, effects and origin. Caryologia, 37 (3), 259-267.

JAMILENA, M., RUIZ REJON, C. AND RUIZ REJON, M. 1990. Variation in the heterochromatin and nucleolar organizing regions of Allium subvillosum L. (Liliaceae). Genome, 33, 779-784.

KODAMA, Y., YoSHIDA, M. C. AND SASAKI, M. 1980. An improved silver staining technique for nucleolus organizer regions by using a nylon cloth. Jpn. J. Hum. Genet., 25, 229-233.

LOIDL, J. 1988. SC- formation in some Allium species, and a discussion of the significance of SC-associated structures and of the mechanism for presynaptic alignment. Pl. Syst. Evol., 158, 117-131.

LOIDL, J. AND GREILHUBER, J. 1983. Structural changes of Agstained nucleolus organizing regions and nucleoli during meiosis in Allium flavum. Can. J. Genet. Cytol., 25, 524-529.
MAGGINI, F. 1975. Homologies of ribosomal RNA nucleotide sequences in monocots. J. Mol. Evol., 8, 317-322.

MAGGINI, F. AND CARMONA, M. J. 1981. Sequence heterogeneity of the ribosomal DNA in Allium cepa (Liliaceae). Protoplasma, 108, 163-171.

NICOLOFF, H., ANASTASSOVA-KRISTEVA, M., RIEGER, R. AND KUNZEL, G. 1979. 'Nucleolar dominance' as observed in barley translocation lines with specifically reconstructed SAT chromosomes. Theor. Appl. Genet., 55, 247-251.

PASTOR, J. 1982. Karyology of Allium species from the Iberian Peninsula. Phyton, 22 (2), 171-200.

PHILlips, R. B., PLEYTE, K. A. AND haRTLEY, S. E. 1988. Stockspecific differences in the number and chromosome positions of the nucleolar organizer regions in arctic char (Salvelinus alpinus). Cytogenet. Cell. Genet., 48, 9-12.

RAYBURN, A. L. AND GILL, B. S. 1985 . Use of biotin-labelled probes to map specific DNA sequences on wheat chromosomes. J. Hered., 76, 78-81.

SAMBROOK, J., FRITSCH, E. F., MANIATIS, T. 1989. Molecular Cloning. A Laboratory Manual. Cold Spring Harbor Laboratory Press, New York.

SATo, s. 1981. Cytological studies on satellited chromosomes of Allium cepa. Caryologia, 34 (4), 431-440.

SCHUBERT, I. AND WOBUS, U. 1985. In situ hybridization confirms jumping nucleolus organizing regions in Allium, Chromosoma, 92, 143-148.

SUZUKI, H., KURIHARA, Y., KANEHISA, T. AND MORIWAKI, K. 1990. Variation in the distribution of silver-staining nucleolar organizer regions on the chromosomes of the wild mouse, Mus musculus. Mol. Biol. Evol., 7 (3), 271-282. 